\title{
Vila Amazonas: antes um espaço "acionado" hoje um passado esquecido
}

\author{
Arilena Nobre Gois \\ Jaqueline Ferreira de Lima Brito \\ Universidade Federal do Amapá - UNIFAP
}

\section{RESUMO}

Um projeto inovador situado no município de Santana no Estado do Amapá, Vila Amazonas se destacou como um centro autônomo, dotado de uma perfeita infra-estrutura, que fugia dos padrões vividos no município. Um trabalho conciso de exemplar aplicação dos princípios modernistas, bem como do urbanismo progressista especificamente no que concerne a cidade industrial, onde a razão determinante de tal estabelecimento é a presença próxima de matéria-prima, existência de uma força natural suscetível e a comodidade dos meios de transportes. O estudo coloca em discussão aspectos importantes da preservação do patrimônio que no momento se encontra na eminência de ser destruído e esquecido.

Palavra- chave: patrimônio, cidade, preservação.

\section{INTRODUÇÃO}

Nesse período, o Amapá era um território federal bem jovem, desprovidos de atividades produtivas modernas e sem qualquer infraestrutura local e serviços; a descoberta de mina de minério de manganês seria um marco para o desenvolvimento regional local. Logo, a partir de 1954 inicio-se a construção do porto, estrada de ferro e área de mineração, incluindo a construção da vila operária denominada de Vila Amazonas. As referências de cidades fechadas industriais surgiram no modelo do urbanismo progressista no final do século XVII na Inglaterra, com Garnier, Gropius e Benoit-Lévy, com a finalidade de atender às atividades econômicas ligadas à exploração de reservas naturais.

O objetivo deste trabalho consiste em analisar a Vila Amazonas em Santana no Amapá, dando enfoque ao Patrimônio do Sítio Histórico herdado para a arquitetura local Amapaense, identificando os elementos 
que preenchem e envolve o espaço arquitetônico, relacionando a materialização do pensamento da época na década de 40, com as intervenções existentes no modelo atual.

O Plano de Preservação de Sítio Histórico Urbano tem como fundamentos o desenvolvimento de ações que se destinam a preservação de sítios urbanos tombados. Este plano busca um equilíbrio entre o valor econômico e cultural dos sítios. No que tange as suas diretrizes, ele busca propiciar o estabelecimento e regulamentos para a orientação, planejamento, e fomento das ações de preservação, considerando os aspectos normativos, estratégicos e operacionais necessários à sua execução.

Quanto aos aspectos normativos ele visa fazer um levantamento de informações sobre o sítio histórico, que no caso é a Vila Amazonas; levando em consideração o diagnóstico da área estabelecendo tanto aspectos do patrimônio cultural como a dinâmica urbana, as carências e as tendências para o desenvolvimento urbano.

Ainda nos aspectos normativos, deve levar em consideração a legislação pertinente a áreas de estudo, destacando o Plano Diretor do Município de Santana, A Lei de Uso e Ocupação do Solo, O Código de Obras do Município, visando assim à adequação das funções urbanas à estrutura físico-espacial a ser preservada e à determinação das potencialidades e vocações para a Vila Amazonas.

Quanto aos aspectos estratégicos, algumas medidas serão estabelecidas para a execução do plano de preservação do sítio, onde destacamos o estabelecimento de estratégias de execução e atuação, cronogramas, elaboração de estudos de impacto e vizinhança e ambiental. No que tange aos aspectos de avaliação, torna-se necessário fazer 0 acompanhamento e a avaliação de melhorias das condições de habitabilidade, e dinamização urbana da área, realizando um paralelo com os padrões de preservação estabelecidos.

Logo, quando se pensa em termos de patrimônio ambiental urbano, não se deve pensar apenas na edificação isolada, porém torna-se necessário, antes de tudo, perceber as relações que os bens naturais e culturais apresentam entre si. Contudo, trata-se agora de ver o meio 
ambiente como fruto dessas relações que acontece de forma intensa e dinâmica no espaço.

\section{CONCEITO DO PATRIMÔNIO MATERIAL.}

A cidade industrial como um ideal imaginário na formação de um local onde se desenvolvam serviços de infra- estrutura, delineando fatores responsáveis pela formação da cidade. Desse modo um complexo industrial inicialmente precisa apresentar fatores que viabilizem o seu correto funcionamento e produção, como a localização do empreendimento fabril, a matéria prima, serviços de transporte (escoamento da produção), energia para o fornecimento tanto para indústria quanto para a cidade.

A investigação do patrimônio industrial no Brasil, que ocorreu durante a década de 1970. Dessa forma, as pesquisas e a preservação do patrimônio industrial no Brasil são ainda simples, no campo teórico, o conhecimento sobre o patrimônio industrial está ainda inserido em valores isolados e pouco conhecidos. No entanto, o patrimônio industrial precisa se estudado inserido na concepção do patrimônio cultural. Conforme analisa Azevedo (2010):

O patrimônio industrial compreende os vestígios da cultura industrial que possuem valor histórico, tecnológico, social, arquitetônico ou cientifico. Estes vestígios englobam edifícios e maquinaria, oficinas, fábricas, minas e locais de processamento e de refinação, entrepostos e armazéns, centros de produção, transmissão e utilização de energia, meios de transporte e todas as suas estruturas e infra-estruturas, assim como os locais em que se desenvolveram atividades sociais relacionadas com a indústria, tais como habitações, locais de culto ou de educação.

Segundo as diretrizes do IPHAN, sobre o enfoque do trabalho, dentro do patrimônio industrial destacamos a importância da vila amazonas, fruto 
do projeto industrial ICOMI no Amapá, destacamos o conceito de bem material:

O patrimônio material protegido pelo Iphan, com base em legislações específicas é composto por um conjunto de bens culturais classificados segundo sua natureza nos quatro Livros do Tombo: arqueológico, paisagístico e etnográfico; histórico; belas artes; e das artes aplicadas. Eles estão divididos em bens imóveis como os núcleos urbanos, sítios arqueológicos e paisagísticos e bens individuais; e móveis como coleções arqueológicas, acervos museológicos, documentais, bibliográficos, arquivísticos, videográficos, fotográficos e cinematográficos.

Os bens culturais materiais tombados podem ser acessados por meio do Arquivo Central do Iphan, que é o setor responsável pela abertura, guarda e acesso aos processos de tombamento, de entorno e de saída de obras de artes do país. O Arquivo também emite certidões para efeito de prova e inscreve os bens nos Livros do Tombo.

\section{CARACTERIZAÇÃO DA ÁREA}




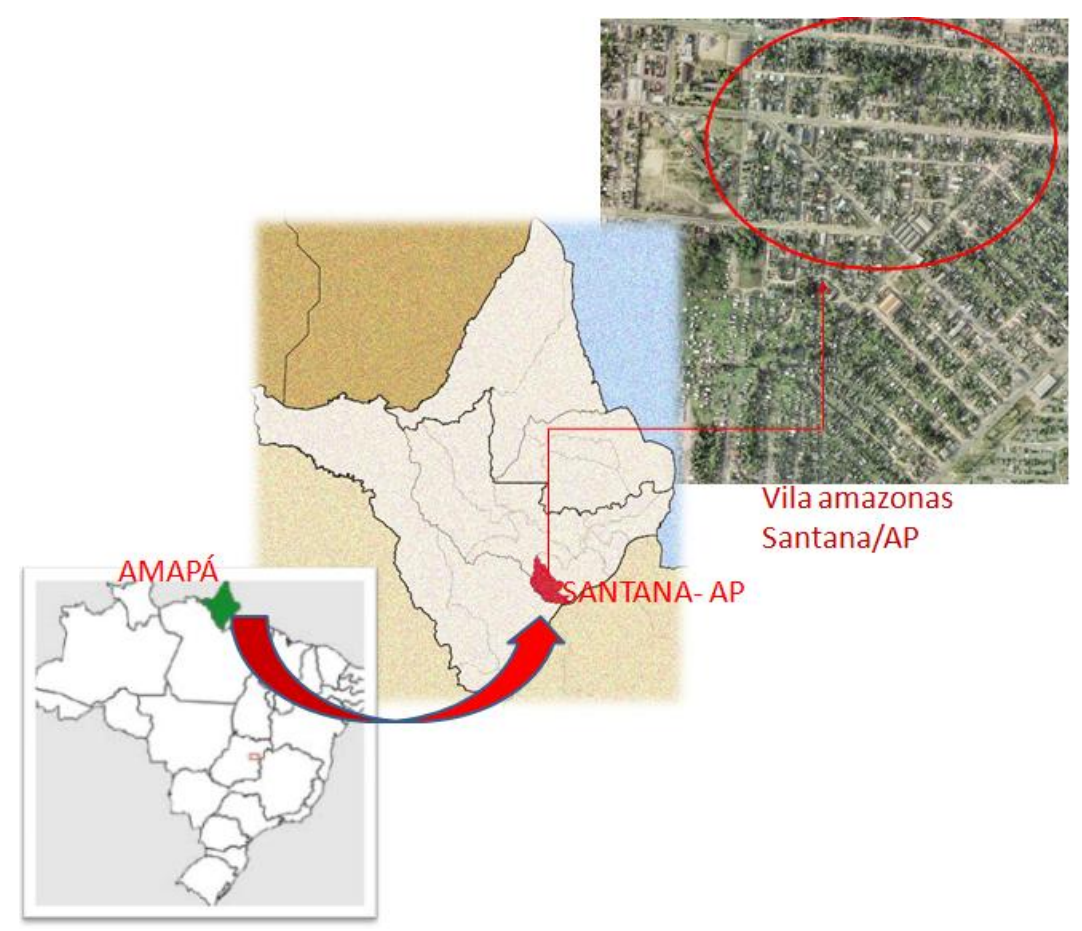

\section{1 ÁREA URBANA}

A área é localizada no Bairro Pertencente ao Município de Santana, localizam-se na parte Sudeste do Município destacando-se como uma área planejada; inserida de acordo com o Plano Diretor em uma Zona Residencial de Baixa Densidade (ZRBD).

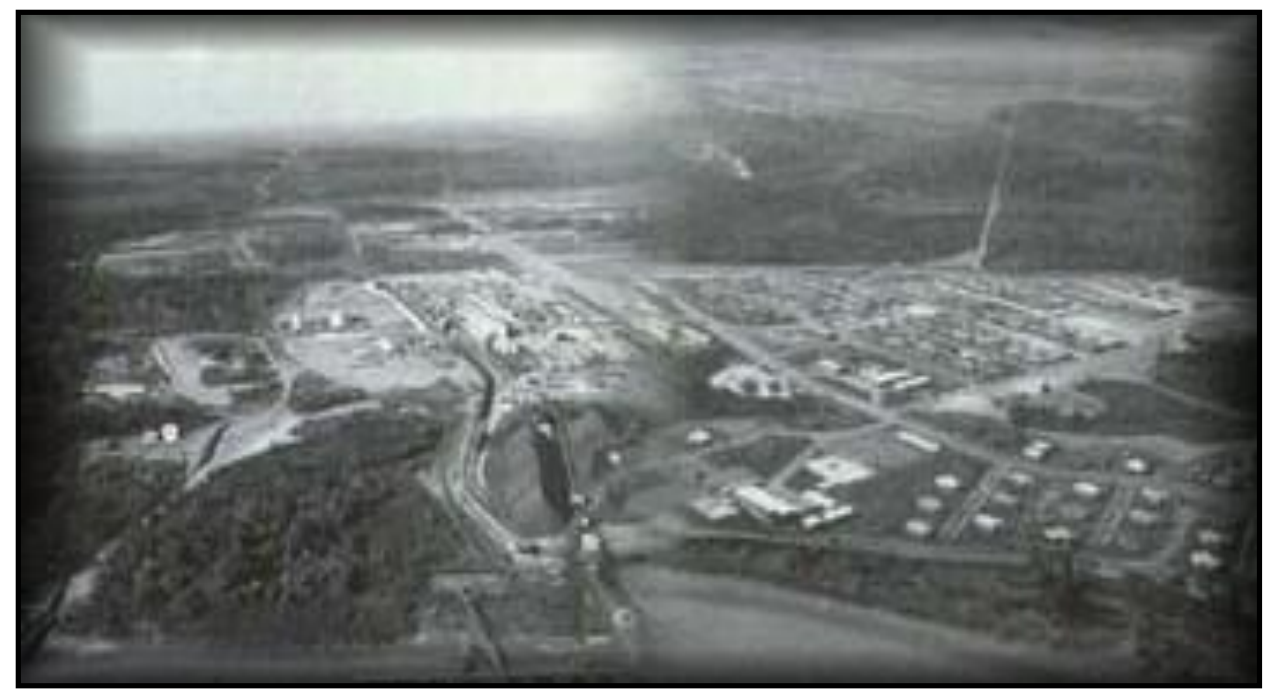

Figura 1.1: Imagem da Vila Amazonas/Santana. Acervo: Museu Joaquim Caetano (Agosto/2009) 
Com a implantação da Indústria e Comércio de Minérios S/A ICOMI, na década de 50, foram implantados grandes projetos na Amazônia. Nesse contexto, destaca-se para essa área a bem estruturada Vila Operária. A origem está atrelada ao processo de descobrimento e exploração de manganês pela Company Town (ICOMI), foi um Empreendimento Planejado a fim de atender aos interesses dos operários da antiga Companhia, destacando alguns equipamentos comunitários como assistência médica, pontos de abastecimento privativos, infraestrutura (vias, saneamento, energia, drenagem) com a finalidade de atender aos funcionários da empresa instalada.

O referente trabalho remete-se a uma abordagem histórica sobre o processo de formação do núcleo urbano que deu origem à cidade de Santana, e de que forma esse espaço sofreu alterações de grande impacto até meados dos últimos anos. Trabalhar-se-á a vida econômica e social desta cidade nas décadas anteriores e os impactos urbanos apresentados no decorrer desse processo até os dias de hoje.

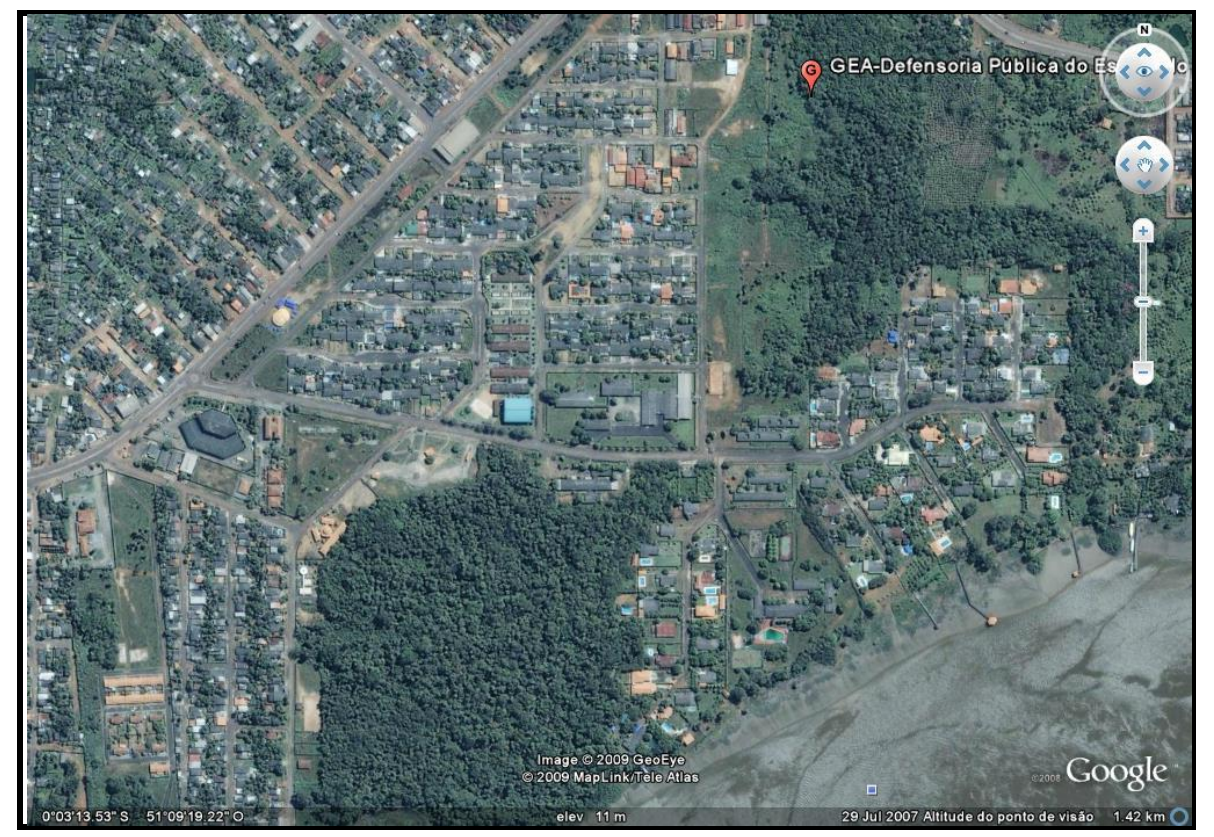

Figura 1.2: Imagem da Vila Amazonas/Santana, Google 2009 Acervo: Jaqueline e Arilena ( agosto/2009)

Uma análise a cerca das transformações ocorridas na cidade de Santana nos anos de 1950, 1960 e 1970 correspondentes ao período no 
qual se instalou e passou a funcionar o Projeto ICOMI, ligado a extração do Manganês na Serra do Navio, mas tendo neste núcleo urbano uma base fundamental para o seu funcionamento; visto que, a cidade tornou-se a área escoradora deste importante minério. Novos bairros, porto fluvial, estrada de ferro, intensificação do comércio local, crescimento populacional, especulação imobiliária e outras transformações estão diretamente ligadas a uma nova forma de existir desse núcleo urbano, contribuindo para as mais variadas implicações; que em alguns casos, tornaram-se negativas devido a sua não manutenção. São fonte imprescindíveis para a comprovação dessas mudanças: registro fotográficos, jornais, história oral, arquivos pessoais e textos eletrônicos. O viés condutor é a história econômica, pois trata da forma como o capital pode exercer influência nos espaços sobre os quais ele avança.

Com o objetivo de alojar o primeiro núcleo habitacional de trabalhadores, a ICOMI construiu na década de 50, a Vila Amazonas. A empresa preparou toda infra-estrutura de saneamento básico de uma grande área no então Distrito, para oferecer melhores condições de moradia aos seus operários. Foram edificados um hospital, um clube recreativo, escola e supermercado. Na Vila até hoje esta é a única área do Município de Santana com rede de esgoto adequada.

Atualmente, as residências que nos remetiam aos projetos norte americanos das cidades jardins foram totalmente desconfigurados, isso decorrente da necessidade promovida pela situação social que muitas famílias adquiriram com o decorrer dos anos, contribuindo para mudanças significativas na caracterização desses espaços. Observa-se a implantação de muros e grades adotados como medida de segurança, paredes arrematadas junto ao teto com a finalidade de diminuir a incidência de insetos nas casas, porém descaracterizando o estudo de partido, pois essas aberturas tinham a finalidade de garantir conforto térmico para as residências.

\subsection{INFRAESTRUTURA}


Quanto à infra-estrutura implantada na Vila Amazonas no período de instalação da empresa na década de 40, foi pensado e executado saneamento básico, drenagem, abastecimento de água, energia, vias, deslocamento de pedestres com calçadas. Porém esses instrumentos não foram conservados, encontrando-se em estado de abandono; foi verificado que hoje a infra-estrutura existente não atende mais a demanda do local.

$\mathrm{Na}$ pavimentação, algumas vias estão em regular estado de conservação. Porém a sinalização vertical e horizontal como também as sinalizações auxiliares é inexistente. Essa falta de sinalização gera ao visitante uma não identificação do espaço, falta de orientação e direcionamento, como também a falta de identidade do local (ver figura 1.3).

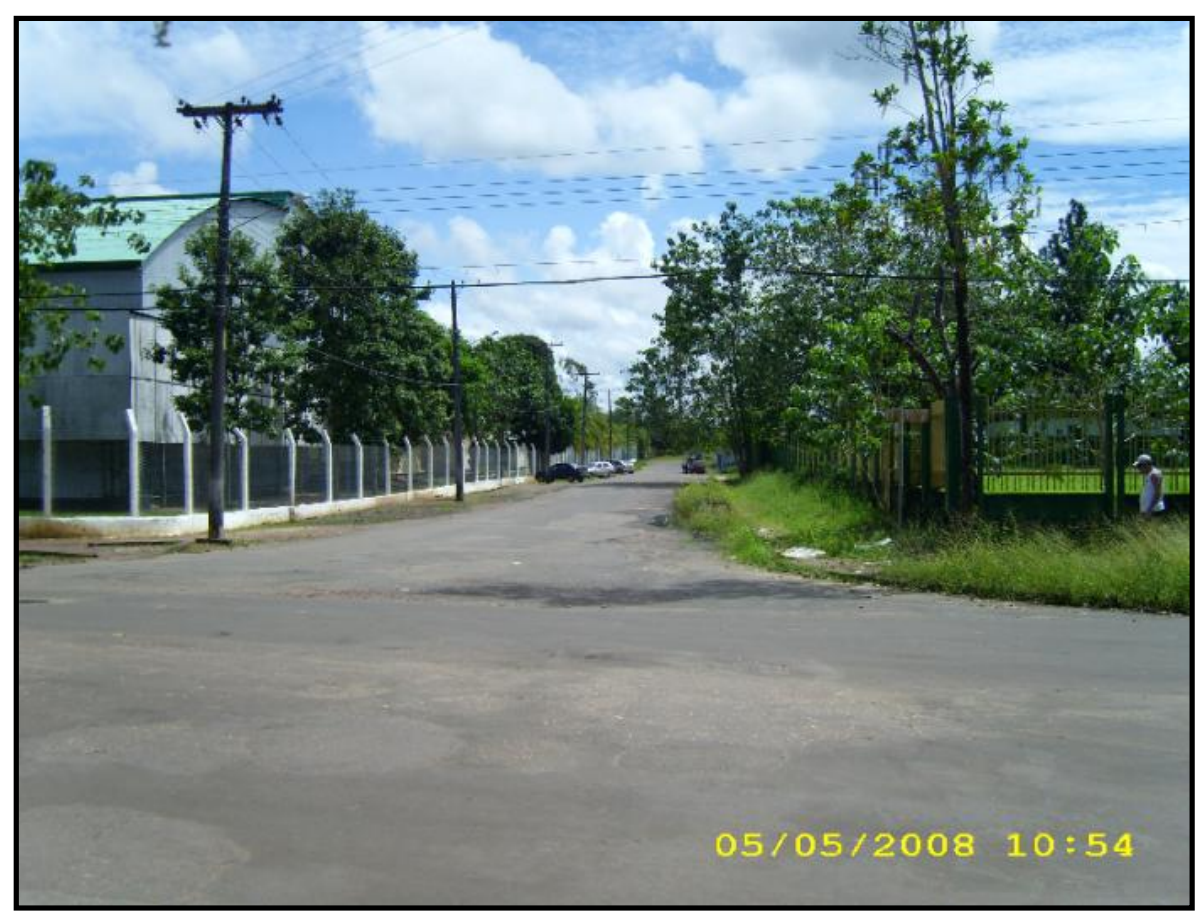

Figura 1.3: Imagem da pavimentação em Vila Amazonas.

Acervo: Jaqueline e Arilena (Agosto/2009)

No que tange ao saneamento básico, o Plano Diretor do Município conceitua que o saneamento é um conjunto de ações que tem como objetivo alcançar níveis crescentes de salubridade, compreendendo, além dos serviços públicos de saneamento básico: abastecimento de água, 
esgotamento sanitário, manejo de resíduos sólidos urbanos e manejo de águas pluviais urbanas; também o controle ambiental de vetores $\mathrm{e}$ reservatórios de doenças.

Em Vila Amazonas, verifica-se que esses mecanismos estão completamente abandonados. Na figura 1.4 observa-se o sistema de drenagem superficial destacando o meio fio e as sarjetas e os passeios públicos em elevado grau de deteriorização.

Já na figura 1.5 verifica-se o sistema de esgotamento sanitário destacando os bueiros em completo estado de abandono.

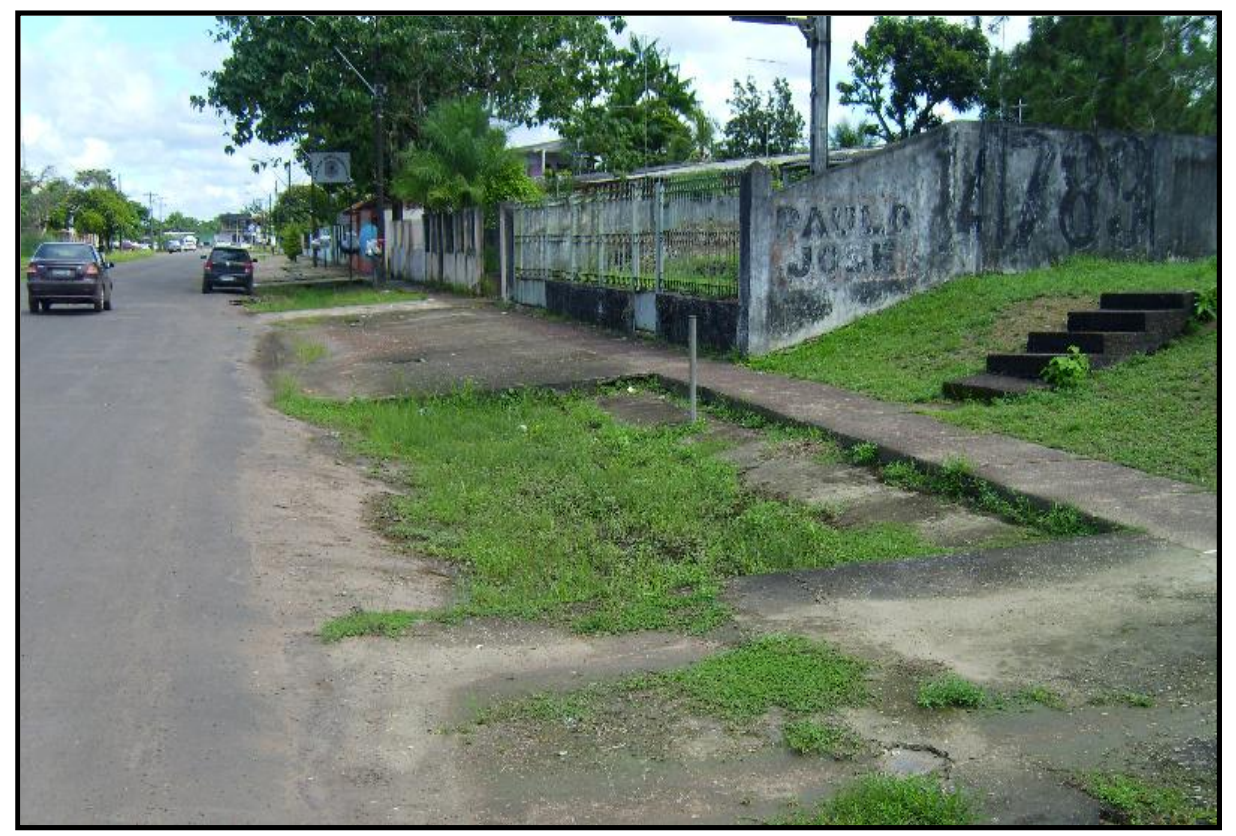

Figura 1.4: Imagem da drenagem superficial e passeios em Vila Amazonas. Acervo: Jaqueline e Arilena (Agosto/2009) 


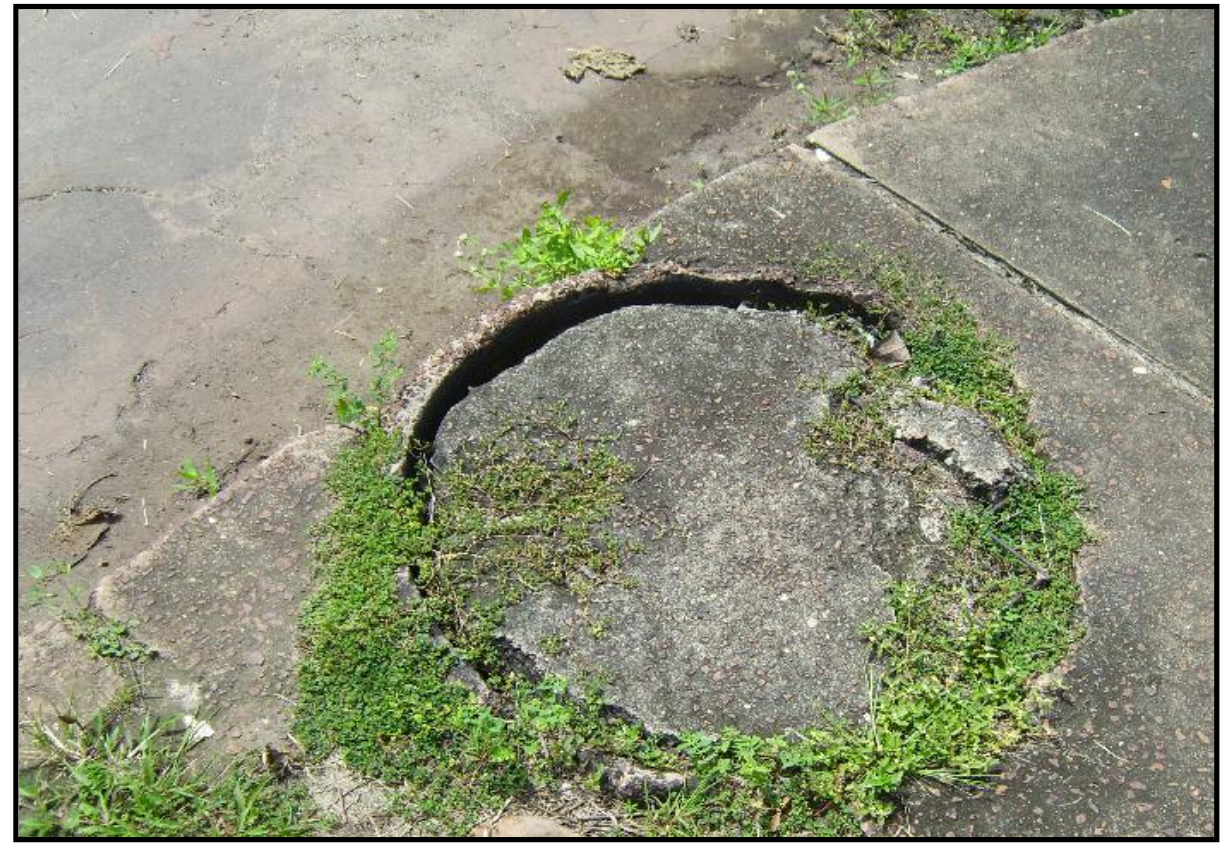

Figura 1.5: Imagem do sistema de esgotamento sanitário em Vila Amazonas

Acervo: Jaqueline e Arilena (Agosto/2009)

\section{3- MOBILIDADE URBANA}

Sobre a mobilidade urbana, o Plano Diretor do Município, trata como sendo ao mesmo tempo causa e conseqüência do desenvolvimento econômico-social, da expansão urbana e distribuição espacial das atividades. Deve-se considerar a relação entre infra-estrutura, transporte motorizado e a questão ambiental. O deslocamento de pessoas e mercadorias influencia fortemente os aspectos sociais e econômicos do desenvolvimento urbano.

O Plano Diretor destaca algumas diretrizes que facilitam a mobilidade urbana, destacando a importância do deslocamento de pedestre, a mobilidade de pessoas com deficiência e restrição de locomoção, priorizar o transporte coletivo, repensar a circulação de veículos observando a existência de sinalizações verticais e horizontais e principalmente repensar o desenho urbano.

No que tange a sinalização urbana, observa-se em Vila Amazonas que são inúmeros os problemas de Sinalização de Trânsito, destacando: 
Sinalização Horizontal (Tachões Luminosos, Faixa de Pedestres, de Carro, de Ciclistas), Vertical (Placas de Velocidade Máxima, Hospitais, Escolas, de Sentido, de Indicação das Áreas) e Luminosas (Semáforos). Em função da estrutura Física e Urbana da Vila Amazonas ser bastante deficitária pela falta de atenção e manutenção do Poder Público (Prefeitura Municipal de Santana), fato este que não ocorria na administração da ICOMI. Tendo em vista que a Vila Amazonas foi projetada com a finalidade de atender diversas atividades em sua área tais como: moradia, lazer, cultura e comercio; características estas que estão se perdendo com tempo.

De posse dessas diretrizes, verifica-se que os maiores problemas que contribuem para a falta de mobilidade urbana seria o acesso de pessoas com deficiência ou mobilidade reduzida se deslocar pela Vila, pois a falta de adequação dos espaços públicos é visivelmente precária.

\subsection{QUANTO A LEGISLAÇÃO}

No que tange a Legislação referente à área estudada, o Plano Diretor do Município destaca algumas diretrizes norteadoras ao referido trabalho, destacando:

$\begin{array}{lccrr} & \text { O Art. } & \text { 48. } & \text { A } & \text { Zona } \\ \text { Residencial de Baixa } & \text { Densidade } & \text { (ZRBD) } & \text { - } \\ \text { Caracteriza-se por } & \text { ser } & \text { de } & \text { uso } \\ \text { predominantemente Residencial, } & \text { foi assim } \\ \text { definida por se tratar de um } & \text { complexo } \\ \text { habitacional denominado Vila Amazonas, } \\ \text { composta de uma boa infra-estrutura. }\end{array}$

O Art. 49. São objetivos da Zona Residencial de Baixa Densidade:

I - Manter as características arquitetônicas existentes;

II - Potencializar meios para

o tombamento de edificações com valor arquitetônico

Histórico; 
III - Evitar o uso inadequado

de atividades que possam desvirtuar o complexo Arquitetônico existente.

A Vila Amazonas (Santana) segundo o Plano Diretor classifica-se como Zona Residencial de Baixa Densidade (ZRBD) e caracteriza-se por ser de uso predominantemente Residencial e com diversos Órgãos Públicos. Foi assim definida por se tratar de um complexo habitacional que é composta de uma boa infra-estrutura, além disso, os objetivos da Zona Residencial de Baixa Densidade destacam-se por: manter as características arquitetônicas existentes, apesar algumas casa já terem sofrido algum tipo de descaracterização, Potencializar meios para o tombamento de edificações com valor arquitetônico histórico e Evitar o uso inadequado de atividades que possam desvirtuar o complexo arquitetônico existente.

Quanto aos aspectos físicos geográficos a Vila Amazonas está localizada em duas áreas distintas Plantas e Inundável: nas Áreas Planas, estão localizadas as Casas, Clube, Mercado, Escola, Setores Públicos (Fórum de Santana, Procuradoria do Estado, Defensoria Pública do Estado, Delegacia Técnico-Científico, Delegacia da Mulher), etc. E compreende aproximadamente cerca de $85 \%$ da área total trabalhada. Nas Áreas Inundáveis, estão localizadas em toda a sua extensão, a exemplo disso: a REVECOM (Reserva Particular do Patrimônio Natural).

\section{IDENTIFICAÇÃO DOS PROBLEMAS URBANOS RELACIONADOS AS EDIFICAÇÕES HISTÓRICAS}

\subsection{ESTADO DE CONSERVAÇÃO E MATERIAIS DISPONÍVEIS}

Como foi verificado na explanação da legislação no item 2.4, na Vila Amazonas deve-se manter as características arquitetônicas existentes e potencializar os meios para o tombamento de edificações com o valor histórico arquitetônico.

As diretrizes que norteiam para essa área é a política de reabilitação, que consiste na gestão de ações integradas, públicas e privadas de recuperação e reutilização de áreas já consolidadas na cidade 
compreendendo os espaços e edificações ociosas, vazias, abandonadas, subutilizadas, insalubres e deterioradas, a melhoria dos espaços e serviços públicos, da acessibilidade e dos equipamentos comunitários.

Porém, a área estuda, encontra-se em um elevado estado de descaracterização destacando o paisagismo, os instrumentos comunitários, áreas institucionais, infra-estrutura e a habitação,

Dentre as suas características físicas, encontramos a Rua Cláudio Lúcio Monteiro de mão dupla, destacamos a existência de aproximadamente 90\% de vias pavimentadas, Hospital, Segurança (Empresa Privada que presta serviços aos moradores), Escola de $1^{0}$ e $2^{\circ}$ grau (Fundação Bradesco: Escola Janary Gentil Nunes), Praça, Portos (Particulares), Serviços de Energia (CEA), Água (Sistema isolado, administrado pela CAESA), Telefonia (Fixa e Móvel), Reserva (RPPN), Estádio Augusto Antunes, Quadra de Esportes, Piscina (sob administração do SESI), Papelarias, Restaurantes e Bares; Casas são geminadas e lotes separados (Muitas casas já mudaram as fachadas e plantas), calçamento e asfaltamento originais.

No que tange aos aspectos históricos de projeto, os núcleos habitacionais projetados pelo arquiteto Oswaldo Arthur Bratke, em 1955, para a exploração do manganês no Amapá, são umas das primeiras propostas de cidades fechadas realizadas no país. Trata-se de um projeto inovador para os padrões de cidade mineradora daquela época, de modo geral, constituídas de instalações provisórias.

Situada no município de Santana, a Vila Amazonas, foi projetada como centro autônomo, dotado de completa infra-estrutura, onde o arquiteto teve condições de expor seu repertório formal e provar que os vários elementos que o compõe nasceram como conseqüência do esforço feito com a finalidade de incorporar, concretamente na forma, as necessidades $\mathrm{e}$ as possibilidades do meio ambiente em que estava interferindo. O projeto para a unidade habitacional é o melhor desempenho do arquiteto neste conjunto magnífico de produção arquitetônica. A larga experiência em projetos residenciais permitiu que Bratke atingisse um modelo perfeito de adequação de programa, condições climáticas, econômicas e materiais disponíveis. 


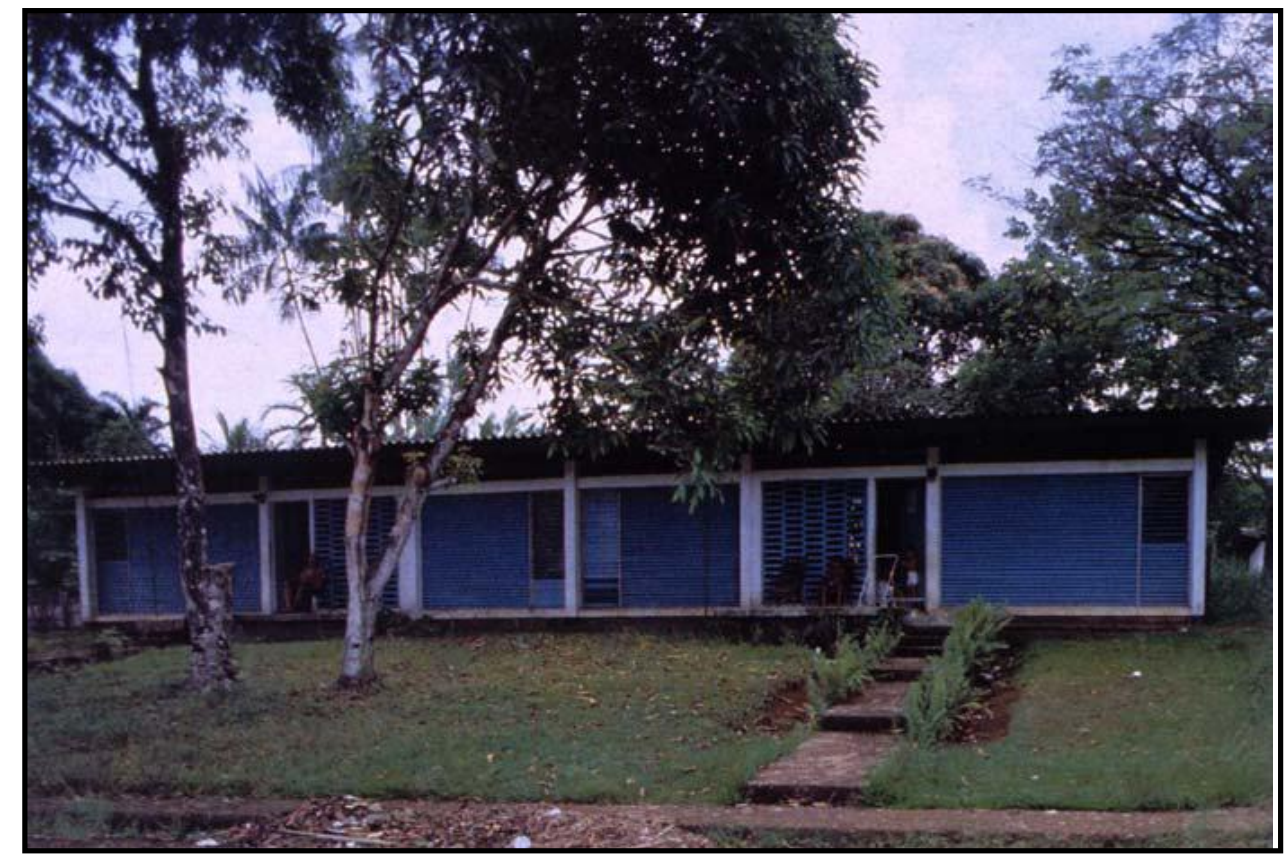

Figura 1.6: Imagem da Habitação Operária Vila Amazonas Acervo: Jaqueline e Arilena(Agosto/2009)

Conhecida como "a casa ecológica", esse seu projeto foi merecedor de vários prêmios, sala especial em Bienal, publicação e comentários da crítica especializada. Um trabalho exemplar de aplicação dos princípios modernos, entretanto na eminência de ser destruído, tendo em vista o fim da concessão para a exploração. A preservação desses núcleos, dada à escala do empreendimento, a sua dinâmica urbana e a sua qualidade arquitetônica, coloca em discussão aspectos importantes da preservação do patrimônio moderno como a integridade dos bens, a sua identidade e, sobretudo o desafio em conciliar a conservação da sua materialidade face ao seu desenvolvimento futuro.

Verificado essas características, observamos que muitas transformações foram realizadas nessa área, mesmo o plano diretor do município tratar como sendo de valor histórico.

\section{AVALIAÇÃO DA ÁREA VISITADA}

\subsection{APOIO INSTITUCIONAIS}


No que tange a presença de apoio institucional tanto público como privados, destacamos na Vila Amazonas a existência de ações voltadas a geração de emprego e renda por meio dos cursos de capacitação do SINE localizado no Complexo do SESI, já os de cunho de qualidade de vida estão presentes nos programas desenvolvidos nas Escolas do Bairro. Programas governamentais (PETI: Programa de Erradicação do Trabalho Infantil), é desenvolvido pela Prefeitura de Santana no Complexo do SESI. A Fundação Bradesco como um órgão privado dando apoio e desenvolvendo projetos para a população local.

\section{CONCLUSÃO}

Por fim, intenta o estudo realizado que, a importância do patrimônio é o reconhecimento por parte da própria comunidade que dele usufrui, preservando e restaurando sem perder a identidade proposta para a época, e que no caso específico de Vila Amazonas está se tornando em um passado esquecido.

No levantamento realizado através da visita em meados de agosto de 2009, observamos que não se foi pensado um plano de preservação para a Vila Amazonas, a área foi planejada, executada, porém não foi mantida. Observa-se uma descaracterização das residências, do espaço urbano, a implantação de outros mecanismos, alteração do espaço e a realização de muitas intervenções.

O objetivo desse estudo é realizar um paralelo do projeto original e o projeto hoje, estudar e analisar as intervenções possíveis, observar a dinâmica do espaço, e o porquê de uma estrutura tão importante da história do Estado do Amapá na era do Manganês, ter sido alterada sem a intervenção de um órgão ou entidades responsáveis para fiscalizar e combater essa modificação tão brusca para o patrimônio.

Assim, o trabalho segue em análises e estudos de intervenções que possam contribuir para a dinâmica do espaço Santanense, reavivando um espaço e gerando fluxos de cultura e história; junto com a implantação da proposta que se consolidou como um Centro Cultural e Histórico de Vila Amazonas. 


\section{REFERÊNCIAS BIBLIOGRÁFICAS}

DRUMMOND, J.A. Investimentos privados, impactos ambientais e qualidade de vida num empreendimento mineral amazônico. 2000.

MINISTÉRIO DAS CIDADES. Plano Diretor Participativo, 2004.

Plano Diretor Participativo de Santana, 2006.

AZEVEDO, Esterzilda Berenstein. Artigo: patrimônio industrial no Brasil.usjt-Arq e Urb( professora associadae-da Universidade Federal da Bahia e coordenadora do Laboratório de Requalificação Urbana. Email: eba0@terra.com.br

Patrimônio material, Disponível: portal.iphan.gov.br/portal/montar PaginaSecao.do?id=12297\&retorno=paginaIphan $>>$ em 25 de setembro de 2010. 